\title{
Welcome Letter from Dr. Montville
}

\author{
Thomas J. Montville
}

Published online: 8 April 2009

(C) Springer Science+Business Media, LLC 2009

In 1997, the first addition of ASM's Food Microbiology Fundamentals and Frontiers devoted but a few paragraphs to the topics of probiotics, stating that empirical evidence argued for a positive affect. In the second edition (2001), a whole chapter covering a vast filed of evidence was devoted to pre-and probiotics. By the third edition (2007), the chapter had significant coverage of molecular and genomic aspects of the field. The field has certainly outgrown the "empirical" label. To be more quantitative, computerized literature searches were conducted to determine the number of papers pertaining to antimicrobial proteins, bacteriocins and probiotics published in the cited year over the last two decades. The combined results showed 22,000 papers in 1980,39,000 papers in 1990, and 56,000 in 2000 ! Clearly, this field has come of age. Clearly, it needs a journal to be its home. My good friend and colleague, Michael Chikindas has championed this cause, guiding Probiotics and Antimicrobial Proteins through the publisher's vetting process and assuming the role of Founding Editor-in-Chief. Under his leadership, the very best papers in on probiotics and antimicrobial papers will be published here, but hopefully not the 73,000 papers projected for publication in 2010.

T. J. Montville $(\bowtie)$

Department of Food Science, Rutgers, The State University, New Jersey, USA

e-mail: montville@aesop.rutgers.edu

\section{Author Biography}

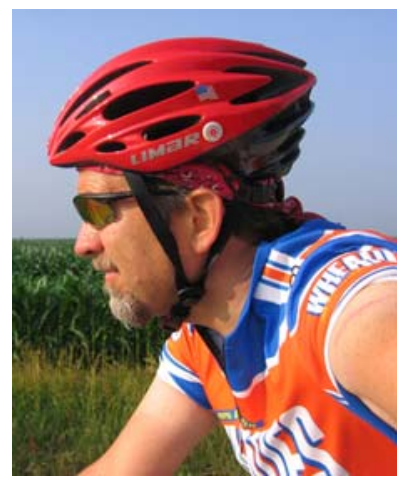

Thomas J. Montville Ph.D., is Professor II (distinguished) of Food Microbiology and has served as both Director of the Graduate Program and Chair of the Department of Food Science at Rutgers, the State University of New Jersey. Dr. Montville received his Ph.D. from MIT, his B.S. from Rutgers and was a Senior Research Microbiologist at the USDA before joining the Rutgers faculty. His research on food safety has special interests in antimicrobial peptides, Clostridium botulinum, Listeria monocytogenes, novel antimicrobials, and, more recently, issues related to protecting the food supply from acts of bioterrorism. He has published over 100 peer-reviewed papers, 11 chapters, and seven books, including two editions of ASM's undergraduate text Food Microbiology-An Introduction. Prof. Montville serves on many other Editorial Boards and the Executive Committee of IFT's Food Microbiology Division. He was a member of the FDA's Food Advisory Committee, IFT's Expert Panel on Antimicrobial Resistance and various USDA NRI Program panels. Dr. Montville is a Fellow of the American Academy of Microbiology and a Fellow of the Institute of Food Technologist. The IFT recently awarded Dr. Montville the Bernard L. Oser Award for Food Ingredient Safety for his pioneering work with antimicrobial proteins and their application to the food industry. In 2009, the "pedaling professor" bicycled across the North American continent, demonstrating that his interests range well beyond the laboratory. 